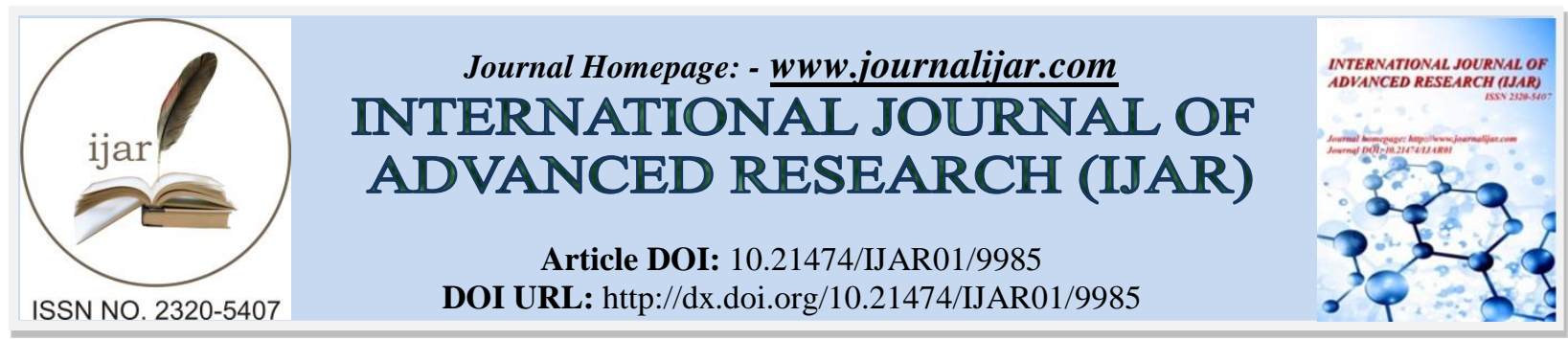

RESEARCH ARTICLE

\title{
EFFECTS OF EARLY MINIMAL ENTERAL NUTRITION IN PRETERM VERY LOW BIRTHWEIGHT INFANTS WITH ABSENT OR REVERSAL OF END DIASTOLIC FLOW IN UMBILICAL ARTERIES (AREDF) BEFORE BIRTH.
}

JayasreeChandramati , Prasanth Karakad and Sasidharan Ponthenkandath.

Division of Neonatology,Amrita Institute of Medical Sciences,Amrita Viswavidyapeetam,Kochi, 682041.

\section{Manuscript Info}

Manuscript History

Received: 05 September 2019

Final Accepted: 07 October 2019

Published: November 2019

\section{Abstract}

Preterm very low birth infants are not fed early if there is shock or severe sepsis or respiratory distress. Traditionally if infants are sick enteral feedings are introduced slowly (at 4-5 days of age). Infants born with history of AREDF are given parenteral nutrition till enteral intake is adequate (7-10 days). We studied the effect of early MEN (at 24 hours of age) in VLBW ( $<32$ weeks gestation) infants with AREDF (MEN group- $n=12$; controls- $n=14$ ). The results of this study reveals that the outcome of infants fed with early MEN is better with shorter length of stay, faster regaining of birth weight, shorter duration of parenteral nutrition and better tolerance of feedings. These data suggest that early MEN can be safely implemented in preterm VLBW infants with history of AREDF with no adverse outcomes.

Copy Right, IJAR, 2019,. All rights reserved.

\section{Introduction:-}

In preterm infants early enteral feeding offers many benefits and has become the standard of care. However on many occasions, this is not possible because of unstable clinical conditions. These conditions include significant hemodynamic instability, severe respiratory distress, septic shock, asphyxia and severe metabolic acidosis because of the risk for the development of necrotizing enterocolitis (NEC). In such states infants are given trophic feeds or minimal enteral nutrition at a rate of 10 to $20 \mathrm{ml} / \mathrm{kg} /$ day enterally along with parenteral nutrition $(1,2,3)$. The risk for NEC may increase if intestinal perfusion is compromised and the above mentioned conditions may compromise gut perfusion. Doppler flow abnormalities of the umbilical arteries is seen in placental insufficiency and is a good monitoring tool for fetal well-being (4,5). Absent or reversal of end diastolic flow (AREDF) in the umbilical artery of the fetus before delivery can lead to compromised organ perfusion and hence infants born with a history of AREDF are not fed for the first few days after birth to minimize the risk for NEC(1). However, minimal enteral nutrition (MEN) has beneficial effects in the mucosal function of small intestine and is recommended in preterm infants with respiratory distress or other clinical conditions (6). Hence we hypothesized that MEN in preterm very low birth weight infants born with history of AREDF will have better outcome.

\section{Methods:-}

This was a prospective controlled study. Infants in the MEN group were kept NPO first 24 hours and enteral feeds were begun with expressed breast milk at $10 \mathrm{ml} / \mathrm{kg}$ for 3 days. Subsequently feeds were increased at $20 \mathrm{ml} / \mathrm{kg} / \mathrm{day}$ daily till full feeds $(150 \mathrm{ml} / \mathrm{kg} /$ day) were attained. The control group were kept NPO for 4 to 5 days and enteral feeds were started at $20 \mathrm{ml} / \mathrm{kg} /$ day and advanced daily at $20 \mathrm{ml} / \mathrm{kg} /$ day till full feeds were attained.

Corresponding Author:-Sasidharan Ponthenkandath.

Address:-Division of Neonatology,Amrita Institute of Medical Sciences,Amrita Viswavidyapeetam, 
The following variables were analyzed. Maternal age, gravida, incidence of hypertension (PIH), maternal medications, gestation at diagnosis, mode of delivery, incidence of chorioamnionitis, APGAR scores, cord pH, birth weight, gestational age, platelet count, feeding intolerance, days to full feeds, days to regain birth weight, incidence of sepsis, length of stay, mortality and incidence of BPD, ROP requiring treatment, grade 3 or $4 \mathrm{IVH}$, PVL and NEC.The primary outcome measures were days to achieve full feeds, postnatal growth, feeding intolerance, incidence of NEC and length of stay.

There were 26 infants enrolled in the study. The mean birthweight of the enrolled infants were $1028 \pm 300$ grams and gestational age was $31 \pm 2.4$ weeks. There were 12 infants in the early MEN group and 14 infants in the control group.There were 7 males in each group $(\mathrm{P}=0.9)$. Antenatal Doppler ultrasounds revealed absent end diastolic flow in all infants and one infant in each group had reversal of flow during diastole. Most of the mothers of the infants (76\%) had elevated blood pressure (PIH).

\section{Results:-}

All infants were delivered by C-section. The mean APGAR scores of the total group was $6.2 \pm 1$ at 1 minute and $7.5 \pm 0.9$ at 5 minutes. There were no differences in the APGAR scores between the groups. There were 3 infants who developed sepsis in the early-MEN group and 5 infants in the control group $(\mathrm{P}=0.7)$. Time to full feeds and regain BW were statistically significant $(\mathrm{p}=0.01)$. MEN group attained full feeds at a mean age of $10.16 \pm 4$ days vs the control group at $17.2 \pm 10$ days $(\mathrm{P}=0.01)$. The mean number of days taken to regain birth weight was $16.18 \pm 5.8$ days in the MEN group vs $20.5 \pm 9.8$ days in the control group $(\mathrm{P}=0.01)$. The mean number of days on parenteral nutrition in the MEN group was $7 \pm 4$ days vs $11.07 \pm 9$ days in the control group $(\mathrm{P}=0.05)$. The length of stay of the MEN group was $38.7 \pm 30$ days vs $56.7 \pm 25$ days in the control group $(\mathrm{P}=0.01)$. The mean discharge weight of the MEN group was $1532 \pm 230$ grams vs $1386 \pm 138$ grams in the control group $(\mathrm{P}=0.06)$. The average postnatal growth were not different between the two groups ( $8 \mathrm{gm} /$ day (MEN group) vs $9 \mathrm{gms} /$ day in the control group). One infant in each group had developed PDA requiring medical management. There were no cases severe IVH (grades 3 or 4), PVL and BPD among these infants. None of the infants developed ROP requiring treatment.

\begin{tabular}{|c|c|c|c|}
\hline table1 & & & \\
\hline & Early MEN $(n=12)$ & Control $(n=14)$ & $\mathrm{P}$ \\
\hline GA (wks) & $32.4 \pm 2.2$ & $30.07 \pm 1.68$ & 0.07 \\
\hline Birth Weight (gms) & $1222 \pm 345$ & $862 \pm 154$ & 0.05 \\
\hline Time to full feeds (days) & $10.16 \pm 4.4$ & $17.23 \pm 10.6$ & 0.01 \\
\hline Regain BW (days) & $16.18 \pm 5.89$ & $20.5 \pm 9.8$ & 0.01 \\
\hline TPN days & $7 \pm 4.3$ & $11.07 \pm 9.32$ & 0.05 \\
\hline LOS (days) & $38.72 \pm 30.2$ & $56.71 \pm 25.5$ & 0.01 \\
\hline Discharge Weight (gms) & $1532.36 \pm 230$ & $1386 \pm 138$ & 0.06 \\
\hline
\end{tabular}

Our data indicate that early MEN group attained full feeds earlier than controls and there were no feeding intolerance in this group. The MEN group had a shorter length of stay. They also regained birthweights faster. These infants required shorter duration of parenteral fluid therapy. There was a slightly lower incidence of sepsis (25\% vs $35 \%$ ) in the MEN group although it was not statistically significant. None of the infants in either group developed NEC. The mean birth weight of infants in the control group was lower with no statistically significant change in the gestational ages between the groups. This is due to a higher incidence of intrauterine growth restriction in the control group.

\section{Discussion:-}

Preterm infants who are born to mothers who had no complications during pregnancy have a good outcome as the gestational age advances beyond 32 weeks $(7,8,9)$. There are several factors that affect the outcome of a preterm infant $(10,11)$. They can be classified as intrauterine (fetomaternal) and extra-uterine (neonatal) factors. Fetal growth is mainly dependent on good placental function and blood flow. As the placental blood flow is impaired fetal nutrition and oxygenation are affected leading to several adverse effects. Initially and transiently fetus may try to redistribute blood flow to vital organs - the brain, heart and adrenals to preserve growth but prolonged placental insufficiency leads to growth restriction of all organs. Organ blood flow is mainly dependent on diastolic flow and if 
diastolic flow is compromised (absent or reversal) it will lead to target organ ischemia(12). The exact mechanism leading to increased resistance in umbilical arteries leading to absent or reversal of flow during diastole is unknown and might be multifactorial $(4,5,13,14,15)$. The speculation is that this may lead also to mesenteric ischemia and might be a risk factor for the development of NEC. So traditionally infants were not fed for the first 4-6 days after birth and feeds were introduced slowly afterwards. The results of our study indicate that early MEN (minimal enteral nutrition) is beneficial in very low birth weight infants with AREDF. They tolerated subsequent feedings well, with faster weight gain and shorter length of stay. There were no cases of NEC.Most (76\%) of the babies were born to mothers who had hypertension. There is a significant correlation of AREDF with PIH as reported previously $(4,5)$. All infants had moderate to severe intrauterine growth restriction which is also seen in women with hypertension during pregnancy. The postnatal weight gain of the infants was suboptimal and all of them developed extra-uterine growth restriction. However, infants in the MEN group had a shorter length of stay and faster achievement of full feeds.They regained their birth weight sooner than control infants without any increased morbidity. These data suggest that infants born to women with ARDEF can be safely fed with minimal enteral nutrition starting at 24 hours of age. The benefits include better tolerance of feeds, faster weight gain and shorter duration of hospital stay with considerable savings on health care costs in developing countries.They also had decreased duration of parenteral nutrition which can lead to less TPN associated and central line associated complications. Thus early introduction of MEN potentially offers several advantages to infants with AREDF. We recommend early MEN in infants born with AREDF starting at least at 24 hours of age. Whether MEN can be introduced even earlier needs to be studied.

\section{References:-}

1. Dorling J, Kempley S, Leaf A. Feeding growth restricted preterm infants with abnormal antenatal Doppler results. Arch Dis Child Fetal Neonatal Ed 2005;90:F359-63.

2. Kamoji VM, Dorling JS, Manktelow B, Draper ES, Fieldet DJ. Antenatal umbilical Doppler abnormalities: an independent risk factor for early onset neonatal necrotizing enterocolitis in premature infants. Acta Paediatr2008;97:327-31.

3. Vishal Vishnu Tewari, Sachin Kumar Dubey, Reema Kumar, Shakti Vardhan, C. M. Sreedhar, and Girish Gupta. Early versus Late Enteral Feeding in Preterm Intrauterine Growth Restricted Neonates with Antenatal Doppler Abnormalities: An Open-Label Randomized Trial. Journal of Tropical Pediatrics, 2018, 64, 4-14

4. Maulik D, Mundy D, Heitmann E, Maulik D. Umbilical artery Doppler in the assessment of fetal growth restriction. Clin Perinatol 2011; 38:65-82

5. Rochelson B, Schulman H, Farmakides G, Bracero L, Ducey J, Fleischer A, Penny B, Winter D. The significance of absent end-diastolic velocity in umbilical artery velocity waveforms. Am J ObstetGynecol 1987; 156: $1213-1218$.

6. Carol Lynn Berseth. Minimal Enteral Feedings. Clinics in Perinatology:1995,Volume 22: 1; 195-205

7. Stevenson, D.K., Wright, L.L., Lemons, J.A. Oh W, Korones SB, Papile LA, Bauer C, Stoll BJ, Tyson JE, Shankaran S, Fanaroff AA, Donovan EF, Ehrenkranz RA, Verter J. Very low birth weight outcomes of the National Institute of Child Health and Human Development Neonatal Research Network, January 1993 through December 1994. Am J Obstet Gynecol. 1998; 179: 1632-1639

8. Fanaroff, A.A., Stoll, B.J., Wright, L.L.,Carlo WA, Ehrenkranz RA, Stark AR, Bauer CR, Donovan EF, Korones SB, Laptook AR, Lemons JA, Oh W, Papile LA, Shankaran S, Stevenson DK, Tyson JE, Poole WK. NICHD Neonatal Research Trends in neonatal morbidity and mortality for very low birthweight infants. Am J Obstet Gynecol. 2007; 196: 147.e1-147.e8

9. Manuck, T.A., Rice, M.M., Bailit, J.L. et al. Preterm neonatal morbidity and mortality by gestational age: a contemporary cohort. (103:e1-14) Am J Obstet Gynecol. 2016; 215

10. Clark RH, Thomas P, Peabody J. Extrauterine Growth Restriction Remains a Serious Problem in Prematurely Born Neonates Pediatrics, 2003, 111 (5) 986-990.

11. Garite TJ, Clark RH, Thorp JA. Intrauterine growth restriction increases morbidity and mortality among premature neonates. American Journal of Obstetrics and Gynecology, 2004,Volume 191, Issue 2, 481-487.

12. Noori S and Istvan Seri. Etiology, Pathophysiology, and Phases of Neonatal Shock. (Chapter 1) in Hemodynamics and Cardiology: Neonatology Questions and Controversies. Book • 2008, Pages 3-18. Editor Kleinman C. Elsevier. ISBN 978-1-4160-3162-8

13. Acharya G, Sonesson SE, Flo K, Rasanan J, Odibo a. Hemodynamic aspects of normal human feto-placental (umbilical) circulation. Acta ObstetGynecolScand 2016; 95: 672-682. 
14. Karsdorp VH, van Vugt JM, van Geijn HP, Kostense PH, Arduim D, Montenegro N, Todros T. Clinical significance of absent or reversed end diastolic velocity waveforms in umbilical artery. Lancet 1994; 344: $1664-1668$.

15. Kiserud T, Ebbing C, Kessler J, Rasmussen S. Fetal cardiac output, distribution to the placenta and impact of placental compromise. Ultrasound ObstetGynecol 2006; 28: 126-136. 